\title{
Uncertainties in modelling the climate impact of irrigation
}

\author{
Philipp de Vrese ${ }^{1} \cdot$ Stefan Hagemann ${ }^{2}$
}

Received: 11 August 2017 / Accepted: 26 October 2017 / Published online: 9 November 2017

(c) The Author(s) 2018. This article is an open access publication

\begin{abstract}
Irrigation-based agriculture constitutes an essential factor for food security as well as fresh water resources and has a distinct impact on regional and global climate. Many issues related to irrigation's climate impact are addressed in studies that apply a wide range of models. These involve substantial uncertainties related to differences in the model's structure and its parametrizations on the one hand and the need for simplifying assumptions for the representation of irrigation on the other hand. To address these uncertainties, we used the Max Planck Institute for Meteorology's Earth System model into which a simple irrigation scheme was implemented. In order to estimate possible uncertainties with regard to the model's more general structure, we compared the climate impact of irrigation between three simulations that use different schemes for the land-surface-atmosphere coupling. Here, it can be shown that the choice of coupling scheme does not only affect the magnitude of possible impacts but even their direction. For example, when using a scheme that does not explicitly resolve spatial subgrid scale heterogeneity at the surface, irrigation reduces the atmospheric water content, even in heavily irrigated regions. Contrarily, in simulations that use a coupling scheme that resolves heterogeneity at the surface or even within the lowest layers of the atmosphere, irrigation increases the average atmospheric specific humidity. A second experiment targeted possible uncertainties related to the representation of irrigation characteristics. Here, in four simulations the irrigation effectiveness (controlled by the target soil moisture and the non-vegetated fraction of the grid box that receives irrigation) and the timing of delivery were varied. The second experiment shows that uncertainties related to the modelled irrigation characteristics, especially the irrigation effectiveness, are also substantial. In general the impact of irrigation on the state of the land surface is more than three times larger when assuming a low irrigation effectiveness than when a high effectiveness is assumed. For certain variables, such as the vertically integrated water vapour, the impact is almost an order of magnitude larger. The timing of irrigation also has non-negligible effects on the simulated climate impacts and it can strongly alter their seasonality.
\end{abstract}

Keywords Irrigation $\cdot$ Land use $\cdot$ Climate impacts $\cdot$ Uncertainty

\section{Introduction}

Irrigation is not only vital for satisfying global food demand, but it also has a distinct impact on climate. Currently, the amount of water that is being redistributed on the land surface via irrigation, is estimated to be more than $2500 \mathrm{~km}^{3} \mathrm{a}^{-1}$ which is equal to about $2 \%$ of precipitation

Philipp de Vrese

philipp.de-vrese@mpimet.mpg.de

Stefan Hagemann

stefan.hagemann@hzg.de

1 Max Planck Institute for Meteorology, Bundesstrae 53, 20146 Hamburg, Germany

2 Helmholtz-Zentrum Geesthacht, Max-Planck-Straße 1, 21502 Geesthacht, Germany over land (Shiklomanov 2000). Studies using a variety of models have investigated how this redistribution affects the availability of freshwater (Döll and Siebert 2002; Tiwari et al. 2009; Liu and Yang 2010; Wada et al. 2012, 2013; Yoshikawa et al. 2013) and climate. The majority of the studies that investigate irrigation's climate impact is focused on regional climate (Douglas et al. 2006; Kueppers et al. 2007; Douglas et al. 2009; Lobell et al. 2009; Saeed et al. 2009; Lawston et al. 2015), but also larger scales have been addressed in recent studies (Boucher et al. 2004; Sacks et al. 2009; Wei et al. 2013; de Vrese et al. 2016a; Krakauer et al. 2016; Thiery et al. 2017). The impact of irrigation has been compared to that of other anthropogenic influences such as deforestation (Gordon et al. 2005; Lobell et al. 2006b), and it has been investigated under changing climate conditions (Lobell et al. 2006a; Puma and Cook 2010; Cook et al. 2011, 
2014). A summary of recent studies can be found in Hagemann et al. (2014).

Even though irrigated areas constitute only about $2 \%$ of the land surface (Siebert et al. 2005, 2013) irrigation strongly alters local, regional and even global climate. Here, Boucher et al. (2004) describe two main mechanisms by which irrigation affects climate, i.e. an evaporative cooling at the surface and an increased absorption of solar radiation higher in the atmosphere, combined with an additional green house effect and condensational heating. Accordingly, the expected impacts of irrigation on the state of the atmosphere are an overall increase in water vapour and a pronounced decrease in temperature close to the surface. With increasing height, the effects due to the additional water vapour in the atmosphere compensate the cooling effects, resulting in a less pronounced decrease or even an increase in temperature higher up in the atmosphere.

There are many other less direct effects. A change in water vapour profile may affect convection, cloud formation and precipitation which could ultimately lead to a decrease in atmospheric water vapour. The same holds for a change in the temperature profile which may affect the saturation mixing ratio of water vapour, convection, cloud formation, precipitation, etc. Sacks et al. (2009) concluded that indirect effects such as a change in cloud cover have an impact at least comparable in magnitude to the evaporative cooling of the surface. Moreover, there are some important regional processes such as the South and East Asian monsoon which can directly be affected by irrigation (Douglas et al. 2009; Lee et al. 2009; Niyogi et al. 2010; Saeed 2011; Saeed et al. 2013; Tuinenburg et al. 2014; de Vrese et al. 2016a). Finally, the advection of water vapor can alter precipitation, cloud cover and surface temperature even in remote regions (Wei et al. 2013; de Vrese et al. 2016a).

The above effects were investigated using a wide range of models and all model-based studies necessarily involve simplifying assumptions, hence they are subject to uncertainties. A prominent example in the context of irrigation is the way water is introduced in the model. One possible approach is to represent irrigation by adding water to the soil whenever the value of an indicator variable passes a certain threshold. In order to simulate irrigation during the growing season, Sacks et al. (2009) added water at a predetermined rate whenever the leaf area index (LAI) in the respective regions was larger than $80 \%$ of the maximum LAI. In this approach the irrigation flux depends exclusively on vegetation characteristics and is independent of the state of the soil. Consequently, the highest water demand is reached at the height of the growing season which, in many regions in the northern hemisphere, is between June and November. In India, the two main cropping seasons, the Kharif (July-October) and the Rabi cropping season (October-March) mainly fall in this period. This is also the monsoon season (summer monsoon
May-September, winter monsoon October-November) in India and Southeast Asia, and the soil in the affected regions exhibits a high moisture content due to pronounced precipitation. Thus, a large share of the water added has little effect on the plant available water, but mainly results in an increase in runoff and drainage. Contrary to this, when introducing irrigation water at a rate that depends on the saturation of the soil, the largest irrigation demand is calculated for the period prior to the monsoon, i.e. March until and May.

For the global scale, there are only few studies which aim at the effects related to differences in the representation of irrigation within models as a key factor of uncertainty. In these studies the focus is mainly on the extent of the irrigated areas or timing and mode of delivery, e.g. Sacks et al. (2009) and Yoshikawa et al. (2013). The present study aims to improve our understanding by performing complementary investigations using the Max Planck Institute for Meteorology's Earth System Model (MPI-ESM, Stevens et al. 2013; Raddatz et al. 2007; Brovkin et al. 2009). The goal is to estimate variations in the impact of irrigation on simulated climate resulting from variations in the modelled irrigation effectiveness and timing of delivery. Here we define the irrigation effectiveness as a measure that relates the crops water requirements to the amount of water which is actually used for irrigation. This measure is different from the more commonly used irrigation efficiency which is used to describe the ratio of water that is evaporated or transpired from irrigated areas and the gross water supply reduced by the amount of effective precipitation (Jensen 2007). In contrast, the irrigation effectiveness relates the gross irrigation to the amount of water required to maintain the soil moisture in the vegetated area close to the level at which plants make optimal use of the water. Thus it indicates the losses that occur because the target soil moisture is above the optimal level, increasing runoff and drainage, and because water is applied to non-vegetated areas.

The impact of irrigation on simulated climate may also differ between models or simulations despite identical assumptions about the irrigation characteristics (Tuinenburg et al. 2014; Krakauer et al. 2016). These differences are related to variations in the setup of the model, the model's structure and its parametrizations. Here, especially the moisture transfer between the surface and the atmosphere and the treatment of irrigated areas as a subgrid-scale feature are important factors. Accordingly, we compare the simulated impact of irrigation between simulations using different schemes for the land-surface-atmosphere coupling to provide a rough estimate for uncertainties related to differences in the model's structure and its parametrizations.

The respective simulations are described in more detail in Sect. 2, together with a brief description of the scheme used to simulate irrigation and the analysis performed in the context of this study. Section 2.1 introduces the irrigation 
scheme, while Sects. 2.2 and 2.3 describe the model setups that were used to investigate uncertainties related to the land-surface-atmosphere coupling (Sect. 2.2) and uncertainties with respect to the modelled irrigation effectiveness and timing of delivery (Sect. 2.3). In Sect. 3, the differences between irrigation simulations and the corresponding reference simulations are analysed to estimate the uncertainties involved in modelling irrigation, i.e. in Sect. 3.1 for uncertainties with respect to the land-surface-atmosphere coupling and in Sect. 3.2 for uncertainties related to the irrigation characteristics. In Sect. 4, the main findings are shortly summarized.

\section{Methods}

All simulations with the MPI-ESM were performed in an AMIP-type setup, i.e. the atmospheric model component coupled to the land surface model with prescribed sea-surface temperature and sea-ice extent (Gates et al. 1999). In this setup, energy is not conserved, but AMIP-type simulations represent the general behaviour of the coupled model well (Hagemann et al. 2013; Stevens et al. 2013). The model was run with a vertical resolution of 47 model levels, of which the lowest is located at a height of roughly $30 \mathrm{~m}$ and a horizontal resolution of T63 $\left(1.9^{\circ} \times 1.9^{\circ}\right)$ which corresponds to a grid-spacing of roughly $200 \mathrm{~km}$.

\subsection{Irrigation scheme}

For the study, the MPI-ESM's land surface model JSBACH was equipped with an irrigation scheme very similar to the one used in a previous study with the MPI-ESM (Tuinenburg et al. 2014; de Vrese et al. 2016a). For the irrigation scheme, dedicated tiles, i.e. subareas within a grid box that have homogeneous characteristics, to represent irrigated crops and the permanent bare soil fraction of a grid box were implemented in JSBACH. The cover fraction of the irrigated tile (Fig. 1) was derived from the potentially irrigated areas taken from the fifth version of the global map of irrigation areas (Siebert et al. 2005, 2013). In the scheme irrigation is modelled by an increase in soil moisture directly, which best resembles irrigation via a flooding of the surface and disregards other reservoirs such as the canopy layer. The amount of water used for irrigation is calculated to maintain the soil moisture within the vegetated part of the irrigated crop tile close to the level at which potential transpiration is reached. The water added by irrigation $I_{c r \text { irr }}^{i}$ in time-step $i$ and the soil moisture in the irrigated crop tile $w_{c r_{-} i r r}^{i, s t a t}$ at the beginning of each time step are calculated based on the saturation of the soil column

$I_{c r_{-} i r r}^{i}=\left(w_{\text {max }} \cdot c_{\text {pot }}-w_{c r_{-} i r r}^{i-1, \text { end }}\right) \cdot v_{c r_{-} \text {irr }}^{i, \text { tart }}$,

$w_{c r_{-} i r r}^{i, s t a r t}=w_{c r \_i r r}^{i-1, \text { end }}+I_{c r \_i r r}^{i}$,

for $w_{c r \text { irr }}^{i-1, \text { end }}<w_{\text {max }} \cdot c_{\text {pot }}$.

Here $w_{\text {max }}$ is the water holding capacity of the soil, $c_{p o t}$ is a coefficient representing the fraction of soil moisture required for transpiration to occur at the potential rate, $w_{c r}^{i-1, \text { end }}$ is the soil moisture in the irrigated tile at the end of the previous time-step and $v_{\text {cr irr }}^{i, \text { istart }}$ is the vegetation ratio at the beginning of the time-step.

\subsection{Setup to investigate the influence of the surface-atmosphere coupling}

In the version of the MPI-ESM that was used in this experiment, three possibilities exist to couple land surface and atmosphere, i.e. a parameter aggregation scheme, a simple flux aggregation scheme (Polcher et al. 1998; Best et al. 2004) and the VERTEX scheme (de Vrese et al. 2016b). In the parameter aggregation scheme, spatial subgrid scale heterogeneity is not accounted for explicitly and with
Fig. 1 Cover fraction of irrigated areas. Black outline shows the focus region in South and Southeast Asia in which about $70 \%$ of the world's irrigated areas are located (SA reagion)

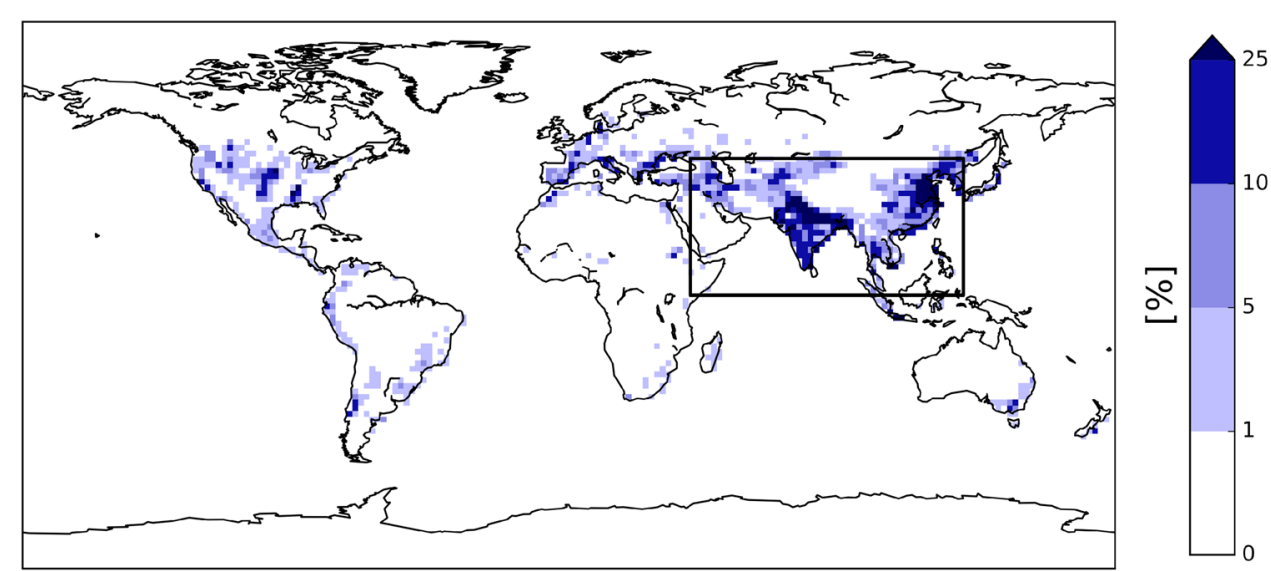


respect to the physical processes the surface is represented by a set of surface characteristics that is valid for the entire gridbox. In the simple flux aggregation, the characteristics of individual tiles are represented explicitly and the state of the surface and the surface fluxes are calculated for the tiles individually. However, it is assumed that the fluxes have blended horizontally below the lowest model level and the entire atmospheric column is assumed to be horizontally homogeneous within a grid box. The VERTEX scheme not only represents tiles explicitly at the surface but also within the lowest three layers of the atmosphere, accounting for subgrid scale variations of temperature and humidity. A more detailed description of these schemes is provided in de Vrese and Hagemann (2016) and a short overview is given in the "Appendix A.1".

Based on the irrigation scheme described above and the three coupling schemes, a three member ensemble was simulated, i.e. $P_{I 1}$ (parameter aggregation), $S_{I 1}$ (simple flux aggregation), $V_{I 1}$ (VERTEX scheme). Each simulation encompasses the same 21-year period (1979-1999) from which the first year was required for the model spin-up and has been omitted from the analysis (Table 1).

\subsection{Setup to investigate the influence of irrigation characteristics}

Moreover, an ensemble of four simulations $\left(V_{I 2}-V_{I 5}\right)$ using the VERTEX scheme was conducted in which certain irrigation characteristics were varied, namely the irrigation effectiveness (via the fraction of water donated to the nonvegetated fraction of the grid box and the target soil moisture in the irrigated fractions) and the timing of delivery. The aim was to estimate the sensitivity to a variation of these characteristics rather than providing the most realistic representation of irrigation. Therefore, the assumptions on which $V_{I 2}-V_{I 5}$ are based present plausible yet extreme scenarios.

In the JSBACH setup used in this study, each tile consists of a vegetated fraction as well as a dynamical bare soil fraction, and irrigation is applied in the entire tile, i.e. vegetated and dynamical non-vegetated fraction alike (note that the permanent bare soil fraction, i.e. the area that is uninhabitable to vegetation, has already been integrated to a dedicated tile). In the model setup used for $P_{I 1}, S_{\mathrm{I} 1}, V_{\mathrm{I} 1}$, it is impossible to control the distribution of water between the vegetated and the non-vegetated fraction of a tile. In order to regulate the amount of water that is being donated to the non-vegetated part of the grid box, the irrigated crop tile was split into two tiles, one representing the vegetated fraction and the other representing the dynamical bare soil share of the irrigated crop tile. In $V_{I 2}-V_{I 5}$ the cover fractions of these tiles and the respective vegetation ratios were not calculated by the model, but were specified based on the properties of the irrigated crop tile simulated in $V_{I 1}$. This was done to ensure that in all simulations the actual area covered by irrigated crops is similar and any difference between the simulations can be attributed to a change in the representation of irrigation characteristics rather than to differences in vegetated area.

For a given simulation $V_{I *}$, the cover fractions of the irrigated crop tile $c f_{c r-i r r, V_{I *}}^{m}$ and the dynamical bare soil tile $c f_{\text {bare_dyn, } V_{I *}}^{m}$ for a given month $m$ were calculated based on the cover fraction $c f_{c r_{-} i r r, V_{I 1}}$ and the vegetation ratio $v_{c r_{-} i r r, V_{I 1}}^{m}$ of the crop tile in simulation $V_{I 1}$

$c f_{c r_{-} i r r, V_{I *}}^{m}=c f_{c r_{-} i r r, V_{I 1}} \cdot v_{c r_{-} i r, V_{I 1}}^{m}$,

Table 1 Simulations with the MPI-ESM and their respective characteristics

\begin{tabular}{|c|c|c|c|c|c|}
\hline Sim. & Coupling scheme & Irrigation applied & Irrigated fraction $(\%)^{\mathrm{a}}$ & Irrigation target & Timing \\
\hline $\mathrm{P}_{\mathrm{R}}$ & Parameter & None & 0.0 & $0.75 w_{\max }$ & - \\
\hline $\mathrm{P}_{\mathrm{I} 1}$ & Parameter & Irrigated crops (vegetated and non-vegetated) & $1.9 *$ & $0.75 w_{\max }$ & Time-step \\
\hline $\mathrm{S}_{\mathrm{R}}$ & Simple flux & None & 0.0 & $0.75 w_{\max }$ & - \\
\hline $\mathrm{S}_{\mathrm{I} 1}$ & Simple flux & Irrigated crops (vegetated and non-vegetated) & $1.9 *$ & $0.75 w_{\max }$ & Time-step \\
\hline $\mathrm{V}_{\mathrm{R}}$ & VERTEX & None & 0.0 & $0.75 w_{\max }$ & - \\
\hline $\mathrm{V}_{\mathrm{I} 1}$ & VERTEX & Irrigated crops (vegetated and non-vegetated) & $1.9 *$ & $0.75 w_{\max }$ & Time-step \\
\hline $\mathrm{V}_{\mathrm{I} 2}$ & VERTEX & Irrigated crops (fully vegetated) & 0.8 & $0.75 w_{\max }$ & Time-step \\
\hline $\mathrm{V}_{\mathrm{I} 3}$ & VERTEX & Irrigated crops (fully vegetated) & 0.8 & $0.75 w_{\max }$ & Biweekly \\
\hline $\mathrm{V}_{\mathrm{I} 4}$ & VERTEX & Irrigated crops (fully vegetated) + bare soil $^{\mathrm{b}}$ & $0.8+1.1$ & $w_{\max }$ & Time-step \\
\hline $\mathrm{V}_{\mathrm{I} 5}$ & VERTEX & Irrigated crops (fully vegetated) + bare soil $^{\mathrm{c}}$ & $0.8+1.0$ & $w_{\max }$ & Time-step \\
\hline
\end{tabular}

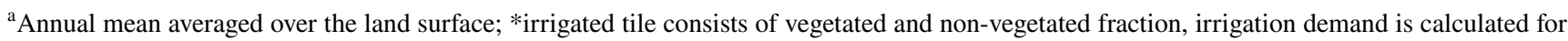
the vegetated fraction but water is applied to the entire tile

${ }^{\mathrm{b}}$ The potentially irrigated area currently not vegetated

${ }^{\mathrm{c}}$ Determined by irrigated vegetated area and the regional irrigation efficiency 
$c f_{\text {bare_dyn, } V_{I *}}^{m}=c f_{c r_{-} i r, V_{I I}} \cdot\left(1-v_{c r \_i r r, V_{I 1}}^{m}\right)$,

$v_{c r-i r r, V_{I *}}^{m}=1.0$.

For $V_{I 2}$ a high irrigation effectiveness is assumed. Accordingly, irrigation is only applied in the fully vegetated irrigated crop tile and no water is supplied to the bare soil tile, i.e. $c f_{\text {bare } i r r, V_{I 2}}^{m}=0.0$.

$V_{I 3}$ is identical to $V_{I 2}$, with the exception of the timing of delivery. For $V_{I 3}$, instead of irrigating at every time step, irrigation is only applied biweekly (every 14 days). The water was applied at the same time-step in all irrigated areas, as studies showed the actual time (of the day) of delivery only has a minor effect (Sacks et al. 2009).

In contrast, for simulations $V_{I 4}$ and $V_{I 5}$ a low irrigation effectiveness is assumed. The simulations were designed to not only account for transpiration from the cropped areas themselves, but to factor in unintended evaporation that occurs during the irrigation process. This evaporation originates in the irrigation of bare soil areas and from parts of the irrigation infrastructure such as reservoirs and channels, the latter of which can not be simulated directly with the MPI-ESM.

In $V_{I 4}$ the irrigated non-vegetated share of the grid box was modelled based on the hypothesis that irrigation is planned to achieve maximum yield, i.e. that the entire area equipped for irrigation will be covered by vegetation at a given point during the growing season. Furthermore, irrigation is required not only when crops are fully grown but already when just shoots are present or even when seeds are planted. Therefore, the irrigated area is assumed to be equal to the area equipped for irrigation and the irrigated bare soil fraction is equal to the share of the potentially irrigated areas not covered by vegetation, i.e. the dynamical bare soil fraction of the irrigated crop tile in $V_{I 1}$

$c f_{\text {bare_irr, } V_{I 4}}^{m}=c f_{\text {bare_dyn, } V_{I 4}}^{m}=c f_{c r \_i r r, V_{I 1}} \cdot\left(1-v_{c r \_i r r, V_{I 1}}^{m}\right)$.

Note that the irrigated vegetated and non-vegetated area in $V_{I 4}$ are similar to those in $V_{I 1}$ and the main difference between the two simulations is given by differences in the target soil moisture as will be explained in more detail later.

In simulation $V_{I 5}$ it was assumed that the amount of water used for irrigation is proportional to the growth of the crops, i.e. most water is required during the height of the cropping season and only very little during the planting stage. Therefore, for $V_{I 5}$ the regional irrigation efficiency $e_{i r r, \text { reg }}$ was used as a very rough approximation for the relation of the cover fractions of the irrigated non-vegetated tile and the irrigated vegetated crop tile (Döll and Siebert 2002)

$c f_{\text {bare_irr, }, V_{I 5}}^{m}=c f_{c r \_i r r, V_{I 1}}^{m} \cdot\left(1 / e_{\text {irr,reg }}-1\right)$, for $c f_{c r \_i r r, V_{I 1}}^{m} \cdot\left(1 / e_{i r r, r e g}-1\right)<c f_{\text {bare_perm, } V_{I 1}}+c f_{\text {bare_dyn, } V_{I I}}^{m}$, otherwise

$c f_{\text {bare_irr, } V_{I 5}}^{m}=c f_{\text {bare_perm, } V_{I 1}}+c f_{\text {bare_dyn, } V_{I 1}}^{m}$,

where $c f_{\text {bare_perm, } V_{I 1}}$ is the permanent bare soil fraction of a grid box.

In many studies the irrigation target soil moisture is equal to the level at which potential transpiration occurs. In JSBACH this is at $c_{p o t}=0.75$. For soils with $w_{\max }>0.4 \mathrm{~m}$ this target level does not induce bare soil evaporation in the irrigated non-vegetated tile, as bare soil evaporation only occurs if water is present in the upper $0.1 \mathrm{~m}$ of the soil reservoir, i.e. when $w_{\text {actual }}>w_{\max }-0.1 \mathrm{~m}$ (Roeckner et al. 1996). In order to estimate the maximum impact on evapotranspiration that an irrigation of the bare soil tile has, the target soil moisture in $V_{I 4}$ and $V_{I 5}$ was set to $w_{i r r}^{i, s t a r t}=w_{\max }$. The plausibility of this assumption depends largely on the represented irrigation technique which can be fundamentally different with respect to the soil moisture level maintained. For certain types, such as drip or sprinkler irrigation, maintaining the soil at saturation level is quite an unrealistic supposition. However, for other techniques such as basin irrigation, a saturated soil is far more plausible. About $80 \%$ of the irrigated area in Asia can be attributed to the cultivation of rice (Seckler et al. 1998). One method to cultivate rice is in form of lowland rice also known as the paddy field, in which rice is planted in an area that is inundated for a large part of the growing season. Around $75 \%$ of the world's rice production is provided by irrigated low land rice fields which maintain saturated soils for at least $80 \%$ of the crops duration. Hence, when considering that rice farming alone constitutes up to $43 \%$ of the global irrigation water demand, a target soil moisture of $w_{\max }$ is a justified supposition (Bouman et al. 2007).

\subsection{Analysis}

Three reference simulations $P_{R}, S_{R}, V_{R}$ were performed which are identical to $P_{I 1}, S_{I 1}, V_{I 1}$ but without irrigation being accounted for. To investigate the impact of irrigation on the simulated state of the surface and the atmosphere, the results of a given irrigation simulation are being compared to the respective reference simulation. To maintain the level of complexity in our analysis as low as possible, we will mainly focus on the two effects described by Boucher et al. (2004) (see Sect. 1) and compare the surface values of irrigation water, surface temperature and heat fluxes and the profiles of atmospheric temperature and specific humidity between irrigation and reference simulations. In the following, the impact corresponding to a specific irrigation simulation, is referenced by $\Delta$ and an index referring to the simulation. For example, $\Delta_{V 3}$ denotes the impact of simulated irrigation 
on a given variable, when using the VERTEX scheme for the surface-atmosphere coupling, assuming a high irrigation effectiveness and a biweekly donation of water, i.e. $\Delta_{V 3}=V_{I 3}-V_{R}$. The differences between the simulations are briefly summarized in Table 1 . To determine whether differences between individual simulations are robust we determined their statistical significance using a two sample, two sided Student's t-test $(\mathrm{p}<0.05)$ and additionally compared them to the MPI-ESM's internal variability (de Vrese et al. 2016a).

Furthermore, we use $\Phi$ to indicate the extent to which the land-surface-atmosphere coupling $\left(\Phi_{\mathrm{PSV} 1}\right)$ and the irrigation scheme $\left(\Phi_{\mathrm{V} 1-5}\right)$ determine the impact of irrigation on a given variable. Based on the coefficient of variance, $\Phi$ denotes the ratio of the standard deviation and the ensemble mean impact:

$\Phi=\frac{\sum_{i=1}^{m} \sigma_{i}}{\sum_{i=1}^{m}\left|\mu_{i}\right|}$

$\sigma_{i}$ refers to the ensemble standard deviation in grid box $i$ and $\mu_{i}$ to the respective mean

$\mu_{i}=n^{-1} \cdot \sum_{j=1}^{n} x_{i, j}^{i r r}-x_{i, j}^{r e f}$,

$\sigma_{i}=\left(n^{-1} \cdot \sum_{j=1}^{n}\left(\left[x_{i, j}^{i r r}-x_{i, j}^{r e f}\right]-\mu_{i}\right)^{2}\right)^{\frac{1}{2}}$,

where a value $x_{i, j}^{i r r}$ pertains to a given irrigation simulation $\mathrm{j}$ and $x_{i, j}^{\text {ref }}$ to the respective reference simulation. It should be noted that $\Phi$ does not constitute a comprehensive quantitative statistical measure as the sampling, i.e. the design of the individual simulations, was arbitrary, thus the sample does not represent the entire population (of possible simulations). Nonetheless, $\Phi$ can be used as a qualitative indicator for possible uncertainties. A small $(<1) \Phi$ signifies that the ensemble mean impact is large compared to the standard deviation and the coupling scheme or the irrigation characteristics only have a minor effect on the simulated impact of irrigation. Accordingly, a large ratio indicates that uncertainties with respect to the coupling scheme or the characteristics are also large. A $\Phi$ substantially larger than 1, indicates that not only the impact's magnitude is uncertain but possibly also its direction, i.e. whether it constitutes an increase or a decrease.

\section{Results}

\subsection{Influence of surface-atmosphere coupling}

The land-surface-atmosphere coupling strongly affects the simulated gross irrigation which ranges between $393 \mathrm{~km}^{3} \mathrm{a}^{-1}$ for $P_{I 1}$ and $1202 \mathrm{~km}^{3} \mathrm{a}^{-1}$ for $S_{I 1}$. The water requirements simulated with the flux aggregation schemes are about three times larger than in the simulation using the parameter aggregation scheme (Table 2, Fig. 2) and in much better agreement with other studies (e.g. Yoshikawa et al. 2013 and references therein). The gross irrigation constitutes only a rough approximation of the amount of water that has a direct impact on the simulated climate, as a significant fraction of the water merely results in increased runoff and drainage. In order to evaluate the amount of climate relevant irrigation water, the differences in evapotranspiration between the irrigation run and the reference run are compared to approximate the net irrigation requirement [often defined as the difference between potential evapotranspiration and evapotranspiration that would occur without irrigation (Döll and Siebert 2002)]. For $\Delta_{P 1}$ and $\Delta_{V 1}$ the increase in evapotranspiration is larger than the initial amount of water applied at the surface. This is because irrigation induces an increase in precipitation which in turn increases soil moisture and evapotranspiration also in the non-irrigated share of the grid box (Seneviratne et al. 2010).

The net vertical moisture flux, i.e. evapotranspiration minus precipitation, can be used as a measure that accounts for the irrigation induced changes in precipitation (Table 2). With respect to the net moisture flux in irrigated grid boxes, the differences between $\Delta_{P 1}, \Delta_{S 1}$ and $\Delta_{V 1}$ are even more pronounced than for gross irrigation. In case of $\Delta_{P 1}$ the irrigation induced change in the moisture flux is actually negative, meaning that the increase in precipitation due to irrigation is larger than the increase in evapotranspiration. For the simulations with the flux aggregation schemes the impact on the moisture flux is much more similar and closer to the gross irrigation amounts. However, $\Delta_{V 1}$ is larger than $\Delta_{S 1}$ despite a smaller gross irrigation. Thus, the ratio between the impact on the moisture flux and the gross irrigation is quite different for $\Delta_{S 1}(0.72)$ and $\Delta_{V 1}(0.88)$, indicating substantial differences in the way irrigation water is transferred to the atmosphere in the two coupling schemes.

The coupling scheme also influences the magnitude of the impact that irrigation has on the simulated climate (Table 3), particularly in the heavily irrigated region of South and Southeast Asia. The region between $40^{\circ} \mathrm{E}$ and $130^{\circ} \mathrm{E} ; 0^{\circ}$ $\mathrm{N}$ and $45^{\circ} \mathrm{N}$ (SA region, see Fig. 1) comprises about $70 \%$ of the world's irrigation areas and almost three quarters of the agricultural water demand (Tatalovic 2009). $\Delta_{P 1}, \Delta_{S 1}$ and $\Delta_{V 1}$ constitute a reduction in the global land surface 


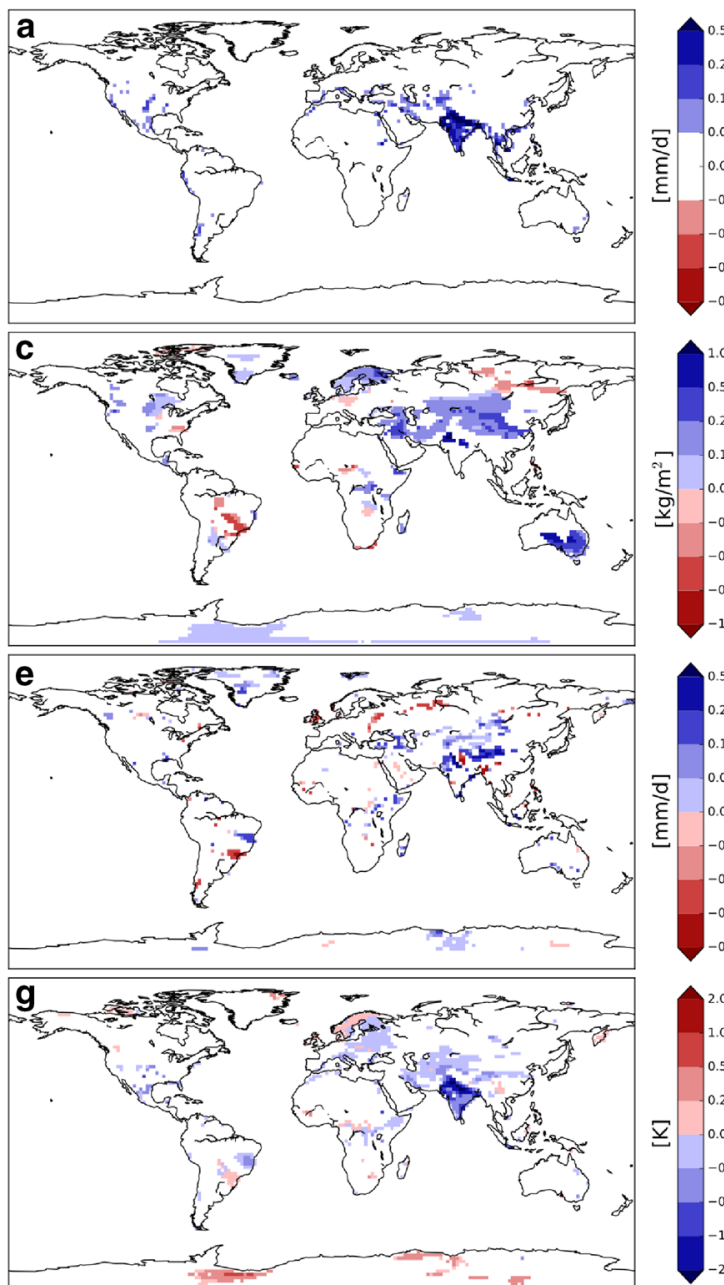

Fig. 2 20-year mean differences between irrigation and reference simulations; ensemble $\left(\Delta_{P 1}, \Delta_{S 1}, \Delta_{V 1}\right)$ mean (a,c,e,g) and $\sigma(\mathbf{b}, \mathbf{d}, \mathbf{f}$, $\mathbf{h})$; $\mathbf{a}, \mathbf{b}$ gross irrigation, $\mathbf{c}, \mathbf{d}$ IWV, $\mathbf{e}, \mathbf{f}$ precipitation, $\mathbf{g}, \mathbf{h}$ surface tem-

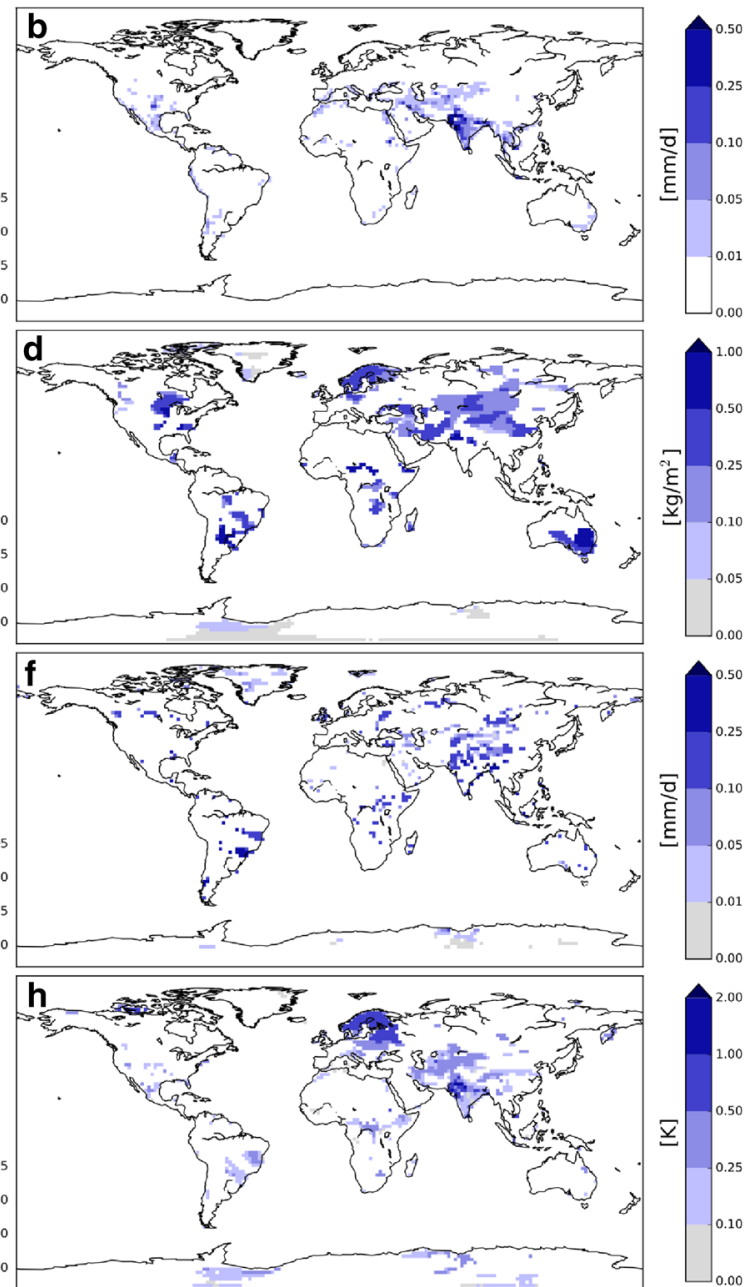

perature; regions with non-robust differences, i.e. non-significant in a Student's t-test $(\mathrm{p}<0.05)$ and below the MPI-ESM's internal variability, have been masked out

Table 2 Gross irrigation requirements, mean difference in evapotranspiration and vertical net moisture flux $\left(\mathrm{km}^{3} \mathrm{a}^{-1}\right)$ for grid boxes in which irrigated fraction $>1 \%$

\begin{tabular}{|c|c|c|c|c|c|c|c|}
\hline & $\Delta_{P 1}$ & $\Delta_{S 1}$ & $\Delta_{V 1}$ & $\Delta_{V 2}$ & $\Delta_{V 3}$ & $\Delta_{V 4}$ & $\Delta_{V 5}$ \\
\hline DJF gross irrig. $\left(\mathrm{km}^{3}\right)$ & 100 & 216 & 214 & 183 & 164 & 1137 & 1079 \\
\hline MAM gross irrig. $\left(\mathrm{km}^{3}\right)$ & 169 & 482 & 472 & 426 & 405 & 1784 & 2154 \\
\hline JJA gross irrig. $\left(\mathrm{km}^{3}\right)$ & 103 & 400 & 382 & 313 & 318 & 1857 & 2409 \\
\hline SON gross irrig. $\left(\mathrm{km}^{3}\right)$ & 21 & 104 & 96 & 97 & 95 & 1454 & 1181 \\
\hline Ann. gross irrig. $\left(\mathrm{km}^{3}\right)$ & 393 & 1202 & 1164 & 1020 & 983 & 6232 & 6823 \\
\hline $\begin{array}{c}E T_{I R R}-E T_{R E F} \\
\left(\mathrm{~km}^{3} a^{-1}\right)\end{array}$ & 405 & 1125 & 1223 & 863 & 944 & 3030 & 3442 \\
\hline Moist. flux $\left(\mathrm{km}^{3} \mathrm{a}^{-1}\right)$ & -59 & 864 & 1019 & 652 & 560 & 2010 & 2453 \\
\hline$\Delta$ bias temp. $(\mathrm{K})$ & $-0.07(0.00)$ & $-0.08(-0.08)$ & $-0.02(-0.17)$ & $-0.04(-0.12)$ & $-0.03(-0.09)$ & $-0.13(-0.28)$ & $-0.08(-0.22)$ \\
\hline$\Delta$ bias precip. $\left(\mathrm{mm} d^{-1}\right)$ & $-0.01(0.03)$ & $0.01(0.03)$ & $-0.01(0.01)$ & $-0.02(-0.00)$ & $-0.01(-0.01)$ & $-0.02(0.01)$ & $-0.01(0.01)$ \\
\hline
\end{tabular}

Change in bias (comparison with WFD) due to irrigation, land-surface mean (SA region) 
Table 3 Mean impact

\begin{tabular}{|c|c|c|c|c|c|c|c|}
\hline $\begin{array}{l}\text { Land-surface mean } \\
\text { (SA region) }\end{array}$ & $\Delta_{P 1}$ & $\Delta_{S 1}$ & $\Delta_{V 1}$ & $\Delta_{V 2}$ & $\Delta_{V 3}$ & $\Delta_{V 4}$ & $\Delta_{V 5}$ \\
\hline Surface temp. $(K)$ & $-0.08(-0.05)$ & $-0.07(-0.23)$ & $-0.04(-0.28)$ & $-0.08(-0.21)$ & $-0.06(-0.16)$ & $-0.21(-0.65)$ & $-0.20(-0.69)$ \\
\hline 2-m temp. $(K)$ & $-0.08(-0.05)$ & $-0.05(-0.17)$ & $-0.03(-0.23)$ & $-0.07(-0.16)$ & $-0.05(-0.12)$ & $-0.17(-0.53)$ & $-0.16(-0.55)$ \\
\hline $\begin{array}{l}\text { srf. net rad. st. (W } \\
\mathrm{m}^{-2} \text { ) }\end{array}$ & $-0.13(-0.06)$ & $-0.24(-0.59)$ & $-0.21(-0.93)$ & $-0.18(-0.30)$ & $-0.18(-0.58)$ & $-0.70(-1.51)$ & $-0.66(-1.53)$ \\
\hline $\begin{array}{l}\text { srf. net rad. lg. (W } \\
\mathrm{m}^{-2} \text { ) }\end{array}$ & $0.12(-0.05)$ & $0.38(1.33)$ & $0.48(2.17)$ & $0.36(1.02)$ & $0.36(1.42)$ & $1.44(4.07)$ & $1.29(4.51)$ \\
\hline $\begin{array}{l}\text { Sens. heat flux (W } \\
\mathrm{m}^{-2} \text { ) }\end{array}$ & $-0.18(-0.34)$ & $-0.53(-1.95)$ & $-0.73(-2.15)$ & $-0.59(-1.42)$ & $-0.51(-1.44)$ & $-1.63(-4.09)$ & $-1.76(-5.11)$ \\
\hline $\begin{array}{l}\text { lat. heat flux (W } \\
\mathrm{m}^{-2} \text { ) }\end{array}$ & $0.18(0.23)$ & $0.67(2.69)$ & $0.98(3.37)$ & $0.75(2.14)$ & $0.69(2.26)$ & $2.37(6.64)$ & $2.40(8.11)$ \\
\hline $\begin{array}{l}\text { Evapotrans. (mm } \\
\mathrm{d}^{-1} \text { ) }\end{array}$ & $0.01(0.01)$ & $0.02(0.09)$ & $0.03(0.12)$ & $0.03(0.08)$ & $0.02(0.08)$ & $0.08(0.22)$ & $0.08(0.28)$ \\
\hline Precip. $\left(\mathrm{mm} \mathrm{d}^{-1}\right)$ & $0.01(0.01)$ & $0.00(0.03)$ & $0.01(0.04)$ & $0.00(0.01)$ & $0.01(0.04)$ & $0.05(0.09)$ & $0.04(0.11)$ \\
\hline IWV (mm) & $-0.01(-0.09)$ & $0.01(0.09)$ & $0.11(0.38)$ & $0.03(0.09)$ & $0.03(0.20)$ & $0.24(0.60)$ & $0.17(0.64)$ \\
\hline Soil moisture (m) & $0.00(-0.00)$ & $0.00(0.01)$ & $0.01(0.02)$ & $0.00(0.02)$ & $0.00(0.02)$ & $0.01(0.03)$ & $0.01(0.03)$ \\
\hline
\end{tabular}

temperature of between $-0.04 \mathrm{~K}\left(\Delta_{V 1}\right)$ and $-0.08 \mathrm{~K}\left(\Delta_{P 1}\right)$, which is in agreement to other global modelling studies (e.g. Puma and Cook 2010 and references therein). Here, the three coupling schemes produce comparable results. However, for the SA region, $\Delta_{P 1}, \Delta_{S 1}$ and $\Delta_{V 1}$ are very different. $\Delta_{V 1}$ corresponds to a surface cooling of $-0.28 \mathrm{~K}$, which is about one fifth larger than $\Delta_{S 1}$ and almost six times more pronounced than $\Delta_{P 1}$. For the sensible and latent heat fluxes, the ratios between $\Delta_{P 1}, \Delta_{S 1}$ and $\Delta_{V 1}$ are in the same order of magnitude.

In the $\mathrm{SA}$ region, $\Delta_{V 1}$ constitutes an average increase in evapotranspiration of $0.12 \mathrm{~mm} \mathrm{~d}^{-1}$ and a precipitation increase of $0.04 \mathrm{~mm} \mathrm{~d}^{-1}$. As a result, there is an increase in the vertically integrated water vapour (IWV) of about $0.38 \mathrm{~mm}$. Also on a global average (including the ocean surface; not shown), the IWV increases by $0.06 \mathrm{~mm}$. In this respect, $\Delta_{V 1}$ behaves very different to $\Delta_{S 1}$ and $\Delta_{P 1}$. In the SA region, $\Delta_{S 1}$ is about 4 times smaller than $\Delta_{V 1}$ and averaged over the entire land surface, the increase in IWV is about 20 times smaller than for $\Delta_{V 1}$. When taking into account the ocean surface, both $\Delta_{S 1}$ and $\Delta_{P 1}$ indicate a drying of the atmosphere due to irrigation, and $\Delta_{P 1}$ also corresponds to a decrease in IWV over land, even in the SA region.

For the investigated variables, $\Phi_{\mathrm{PSV} 1}$ within the SA region, ranges between 0.58 and 1.07 with an average of 0.81 . This indicates that, even though there is a certain amount of variation between $\Delta_{P 1}, \Delta_{S 1}$ and $\Delta_{V 1}$, the impact of simulated irrigation on this region is on average larger than the uncertainty due to differences in the surface-atmosphere coupling (Table 4). However, for some of the variables this is not the case, most prominently IWV. Here, $\Phi_{\mathrm{PSV} 1}$ is larger than 1 ., which reflects well that between $\Delta_{P 1}, \Delta_{S 1}$ and $\Delta_{V 1}$ there is no agreement on whether the atmosphere becomes on average drier or moister due to irrigation. For the entire land surface, $\Phi_{\mathrm{PSV} 1}$ is on average 1.08 showing that the simulated impact of irrigation is even more uncertain when taking

Table $4 \Phi$

\begin{tabular}{llll}
\hline $\begin{array}{l}\Phi \text {; land-surface mean (SA } \\
\text { region) }\end{array}$ & $\Delta_{P 1}, \Delta_{S 1}, \Delta_{V 1}$ & $\Delta_{V 1}, \Delta_{V 2}, \Delta_{V 3}, \Delta_{V 4}, \Delta_{V 5}$ & All simulations \\
\hline Surface temp. (-) & $1.16(0.75)$ & $0.43(0.30)$ & $0.97(0.83)$ \\
2-m temp. (-) & $1.26(0.77)$ & $0.45(0.35)$ & $1.00(0.85)$ \\
srf. net rad. st. (-) & $1.32(1.07)$ & $0.55(0.56)$ & $1.12(0.96)$ \\
srf. net rad. lg. (-) & $1.13(0.85)$ & $0.48(0.40)$ & $0.98(0.85)$ \\
Sens. heat flux (-) & $0.88(0.58)$ & $0.41(0.32)$ & $0.92(0.73)$ \\
Lat. heat flux (-) & $0.81(0.59)$ & $0.38(0.29)$ & $0.90(0.75)$ \\
Evapotrans. (-) & $0.81(0.59)$ & $0.38(0.29)$ & $0.90(0.75)$ \\
Precip. (-) & $1.01(0.79)$ & $0.50(0.45)$ & $1.03(0.84)$ \\
IWV (-) & $1.44(1.06)$ & $0.60(0.54)$ & $1.08(0.94)$ \\
Soil moisture (-) & $0.91(0.80)$ & $0.33(0.16)$ & $0.81(0.65)$
\end{tabular}


Fig. 3 20-year mean differences between irrigation runs $P_{I 1}, S_{I 1}, V_{I 1}$ and reference runs $P_{R}, S_{R}, V_{R}$, a temperature, $\mathbf{b}$ specific humidity; solid lines refer to the SA region $\left(40^{\circ} \mathrm{E}\right.$ $-130^{\circ} \mathrm{E} ; 0^{\circ} \mathrm{N}-45^{\circ} \mathrm{N}$ ), dashed lines to the entire land surface
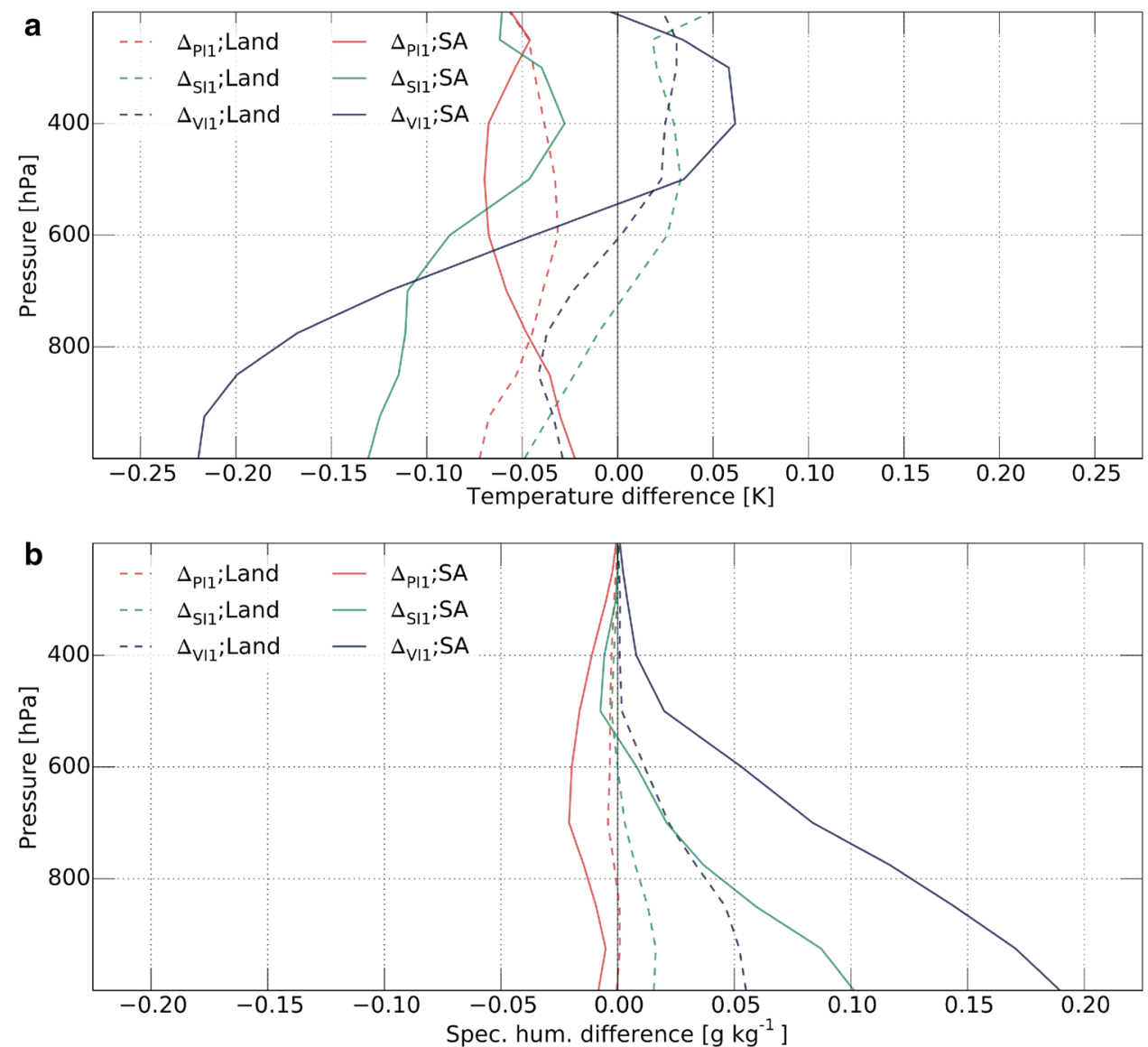

into account remote impacts and impacts in regions that are less heavily irrigated. As in the SA region, the simulations agree least on the global impact on IWV $\left(\Phi_{\mathrm{PSV} 1}=1.44\right)$. This indicates that the coupling scheme effects the impact of irrigation throughout the entire atmosphere and not only on the near-surface climate (Fig. 3). It should be noted that, in the following, we focus on the atmospheric column up to a height of about $200 \mathrm{hpa}$. There are also visible effects higher in the atmosphere but these are much less systematic, and a detailed discussion of these effects is beyond the scope of this study.

When using the parameter aggregation $\left(\Delta_{P 1}\right)$, the specific humidity in the SA region is lower in the irrigation run throughout the entire atmospheric column. Furthermore, the vertical column is consistently colder. Here, the strongest cooling does not appear close to the surface, where the evaporative cooling effect is the strongest, but higher up in the atmosphere. This indicates that the cooling of the surface and the corresponding decrease in sensible heat flux are not exclusively responsible for the cooling of the atmosphere and that the two main mechanisms discussed in Sect. 1 are not the dominant ones in $P_{I 1}$.

In contrast $\Delta_{V 1}$ and $\Delta_{S 1}$ are consistent with these mechanisms, i.e. a strong increase in atmospheric water vapour, a strong evaporative cooling at the surface and a less pronounced cooling or even a warming higher up in the atmosphere. However, for $\Delta_{V 1}$ the respective effects are much more pronounced. Close to the surface, where $\Delta_{V 1}$ and $\Delta_{S 1}$ both constitute an increase in specific humidity in the SA region, $\Delta_{V 1}$ is almost twice as large as $\Delta_{S 1}$. Averaged over the entire land surface, the increase in specific humidity is much smaller, but the ratio between $\Delta_{V 1}$ and $\Delta_{S 1}$ is even larger, and close to the surface, $\Delta_{V 1}$ is more than three times larger than $\Delta_{S 1} . \Delta_{V 1}$ and $\Delta_{S 1}$ also differ with respect to the temperature profile. In the SA region, the evaporative cooling effect close to the surface for $\Delta_{V 1}$ is more than two thirds larger than for $\Delta_{S 1}$, and above $6000 \mathrm{~m}, \Delta_{V 1}$ constitutes a warming of the atmosphere due to irrigation. Here, the latent heat release due to condensation in combination with the increase in radiation absorbed dominates any cooling effects related to a decrease in the surface sensible heat flux. This behaviour can not be found for $\Delta_{S 1}$. Even though the temperature decrease becomes less pronounced with increasing height, the irrigation run consistently exhibits lower temperatures in the atmosphere. Thus, while $\Delta_{V 1}$ and $\Delta_{S 1}$ exhibit similar tendencies, these are roughly twice as pronounced for $\Delta_{V 1}$. Note that a more detailed analysis of these effects is given in the "Appendix A.2". 

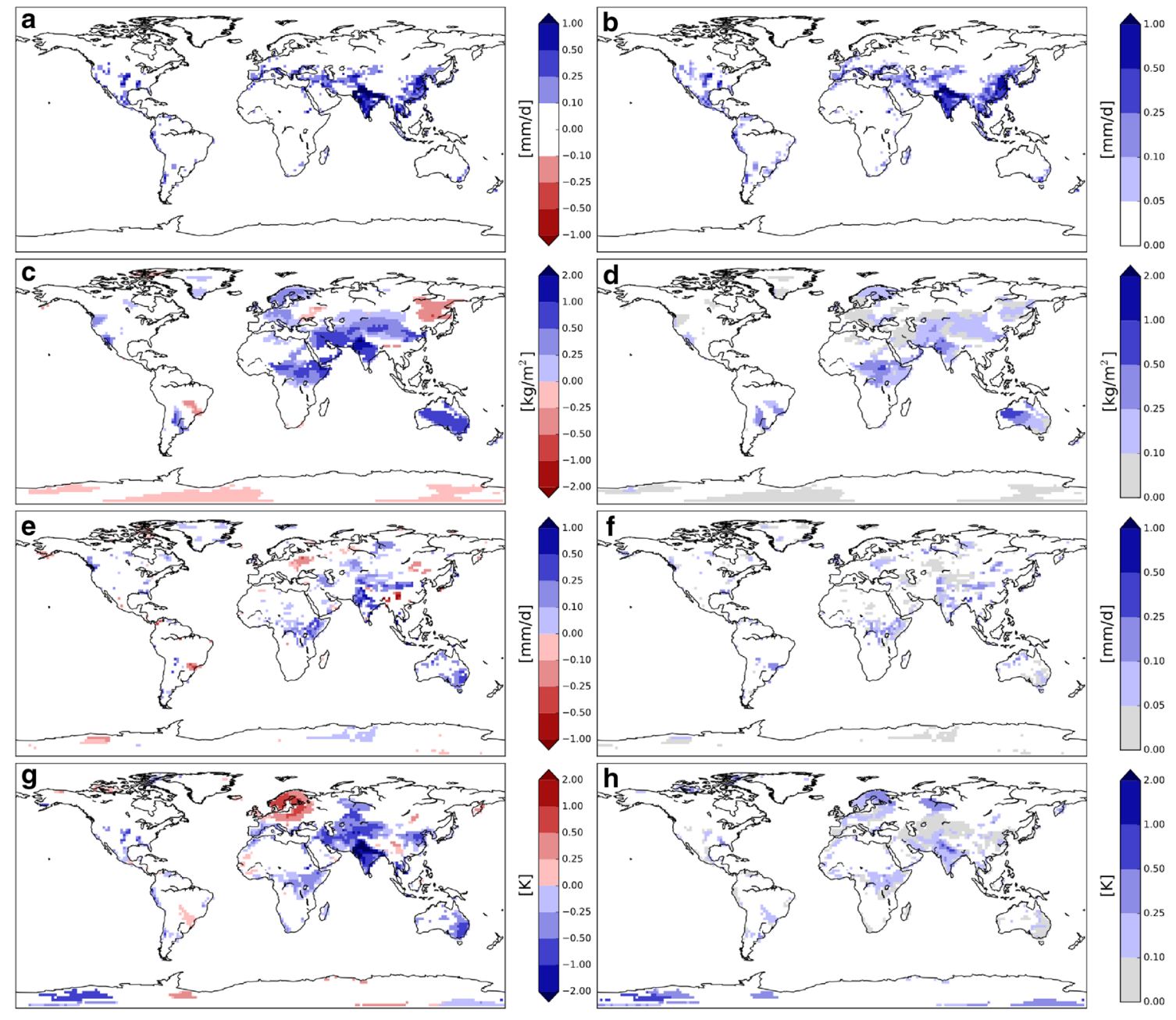

Fig. 4 20-year mean differences between irrigation and reference simulations; ensemble $\left(\Delta_{V 1}, \Delta_{V 2}, \Delta_{V 3}, \Delta_{V 4}, \Delta_{V 5}\right)$ mean (a, c, e, g) and $\sigma(\mathbf{b}, \mathbf{d}, \mathbf{f}, \mathbf{h}) ; \mathbf{a}, \mathbf{b}$ gross irrigation, $\mathbf{c}, \mathbf{d}$ IWV, e, f precipitation, $\mathbf{g}$,

\subsection{Influence of irrigation characteristics}

The assumed irrigation characteristics, especially the irrigation effectiveness, greatly affect the simulated water requirements. The gross irrigation is between roughly 5 and 7 times larger in the simulations assuming a low irrigation effectiveness than in the two simulations with a high irrigation effectiveness (Table 2, Fig. 4). The gross irrigation for $V_{I 4}\left(6232 \mathrm{~km}^{3} \mathrm{a}^{-1}\right)$ and $V_{I 5}\left(6823 \mathrm{~km}^{3} \mathrm{a}^{-1}\right)$ is exceedingly large, which can partly be explained by an unrealistic increase in runoff and drainage. In reality, embankments prohibit runoff from inundated rice fields or the runoff is channelled to downstream fields. In the model these constructive constrains are not accounted for, so that more than half of the water used for irrigation is lost through runoff and drainage.

The impact on the net vertical moisture flux is also strongly affected by the assumed irrigation characteristics h surface temperature; regions with non-robust differences, i.e. nonsignificant in a Student's $t$ test $(\mathrm{p}<0.05)$ and below the MPI-ESM's internal variability, have been masked out

and the impact in the high effectiveness scenarios, i.e. $652 \mathrm{~km}^{3} \mathrm{a}^{-1}$ for $\Delta_{V 2}$ and $560 \mathrm{~km}^{3} \mathrm{a}^{-1}$ for $\Delta_{V 3}$, amounts to less than a third of $\Delta_{V 4}\left(2010 \mathrm{~km}^{3} \mathrm{a}^{-1}\right)$ and only about a quarter of $\Delta_{V 5}\left(2453 \mathrm{~km}^{3} \mathrm{a}^{-1}\right)$. Furthermore, $\Delta_{V 2}$ is about $15.0 \%$ smaller than $\Delta_{V 3}$, indicating that also the timing of irrigation may have an important impact on climate. However, in comparison to the differences between simulations with a high and a low irrigation effectiveness, the respective effects can be expected to be an order of magnitude smaller. The same is true for a comparison of $\Delta_{V 4}$ and $\Delta_{V 5}$, with the difference in net vertical moisture flux being about $20.0 \%$ smaller for $\Delta_{V 4}$. There are also substantial differences in the seasonality of irrigation and the relative amount of water applied during boreal spring and summer is more than a third larger for $\Delta_{V 5}$. Therefore, also the impacts on climate due to irrigation are larger for $\Delta_{V 5}$ than for $\Delta_{V 4}$ during these seasons (not shown). In turn $\Delta_{V 4}$ exhibits larger relative irrigation amounts and 
consequently larger impacts during autumn and winter. As the winds transporting water vapour vary on a seasonal scale (de Vrese et al. 2016a), these differences affect the remote impacts of irrigation. However, a detailed seasonal comparison would go beyond the scope of this work. Thus, it should be acknowledged that also the differences between $\Delta_{V 2}$ and $\Delta_{V 3}$ and between $\Delta_{V 4}$ and $\Delta_{V 5}$ are not negligible but in order to give a rough estimate of possible uncertainties involved in modelling irrigation, it is sufficient to focus on the differences related to the irrigation effectiveness.

As could be expected from the experimental setup, the impact of irrigation on the state of the surface is much more pronounced in the simulations with a low irrigation effectiveness (see Fig. 4; Table 3). For most variables, $\Delta_{V 4}$ and $\Delta_{V 5}$ are about three to four times larger than $\Delta_{V 2}$ and $\Delta_{V 3}$. On global average, the decrease in the (land) surface temperature ranges between roughly $-0.07 \mathrm{~K}\left(\Delta_{V 2}\right.$ and $\left.\Delta_{V 3}\right)$ and $-0.21 \mathrm{~K}\left(\Delta_{V 4}\right.$ and $\left.\Delta_{V 5}\right)$. Here, the cooling in the two low irrigation effectiveness scenarios is also substantially larger than for $\Delta_{P 1}, \Delta_{S 1}$ and $\Delta_{V 1}$. However, it is well within the bounds estimated for extreme irrigation scenarios, e.g. Lobell et al. (2006b) estimated an possible cooling of the land surface by $-1.31 \mathrm{~K}$ due to an irrigation of all cropland. In the SA region the respective values range between $-0.16 \mathrm{~K}\left(\Delta_{V 3}\right)$ and $-0.69 \mathrm{~K}\left(\Delta_{V 5}\right)$. For the IWV the differences between the simulations with high and low effectiveness are even more pronounced. Here, $\Delta_{V 4}$, with an increase of $0.24 \mathrm{~mm}$, is about 8 times larger than $\Delta_{V 2}$ and $\Delta_{V 3}(0.03 \mathrm{~mm})$, and in the SA region, $\Delta_{V 4}$ is still 6 times larger than $\Delta_{V 2}$ and 3 times larger than $\Delta_{V 3}$. Here, $\Delta_{V 3}$ is also twice as large as $\Delta_{V 2}$, which confirms that differences due to the timing of delivery are non-negligible, even though they are much smaller than the differences related to the irrigation effectiveness.

For most variables, the differences between $\Delta_{V 2}, \ldots, \Delta_{V 5}$ are larger than those between $\Delta_{P 1}, \Delta_{S 1}$ and $\Delta_{V 1}$, so that the ensemble standard deviation $\sigma_{V 1-5}$ is larger than $\sigma_{P S V 1}$. However, because also the ensemble mean impact $\mu_{V 1-5}$ is much larger than $\mu_{P S V 1}$ the uncertainty due to differences in the irrigation characteristics is roughly only half the uncertainty that is associated with differences in the coupling scheme. In the SA region the values of $\Phi_{\mathrm{V} 1-5}$ are predominantly below 0.5 (Table 4). Here, it is noteworthy that the variable with the lowest $\Phi_{\mathrm{V} 1-5}$ is soil moisture ( 0.33 for the land surface and 0.16 for the SA region). The prescribed irrigated area and the target soil moisture vary strongly between $\Delta_{V 2}, \Delta_{V 3}, \Delta_{V 4}$ and $\Delta_{V 5}$. Nonetheless, in the SA region $\sigma_{V 1-5}$
Fig. 5 20-year mean differences between irrigation runs $V_{I 2}-V_{I 5}$ and reference run $V_{R} \mathbf{c}$ temperature, $\mathbf{d}$ specific humidity; solid lines refer to the $\mathrm{SA}$ region $\left(40^{\circ} \mathrm{E}-130^{\circ} \mathrm{E} ; 0^{\circ} \mathrm{N}-45^{\circ} \mathrm{N}\right)$, dashed lines to the entire land surface
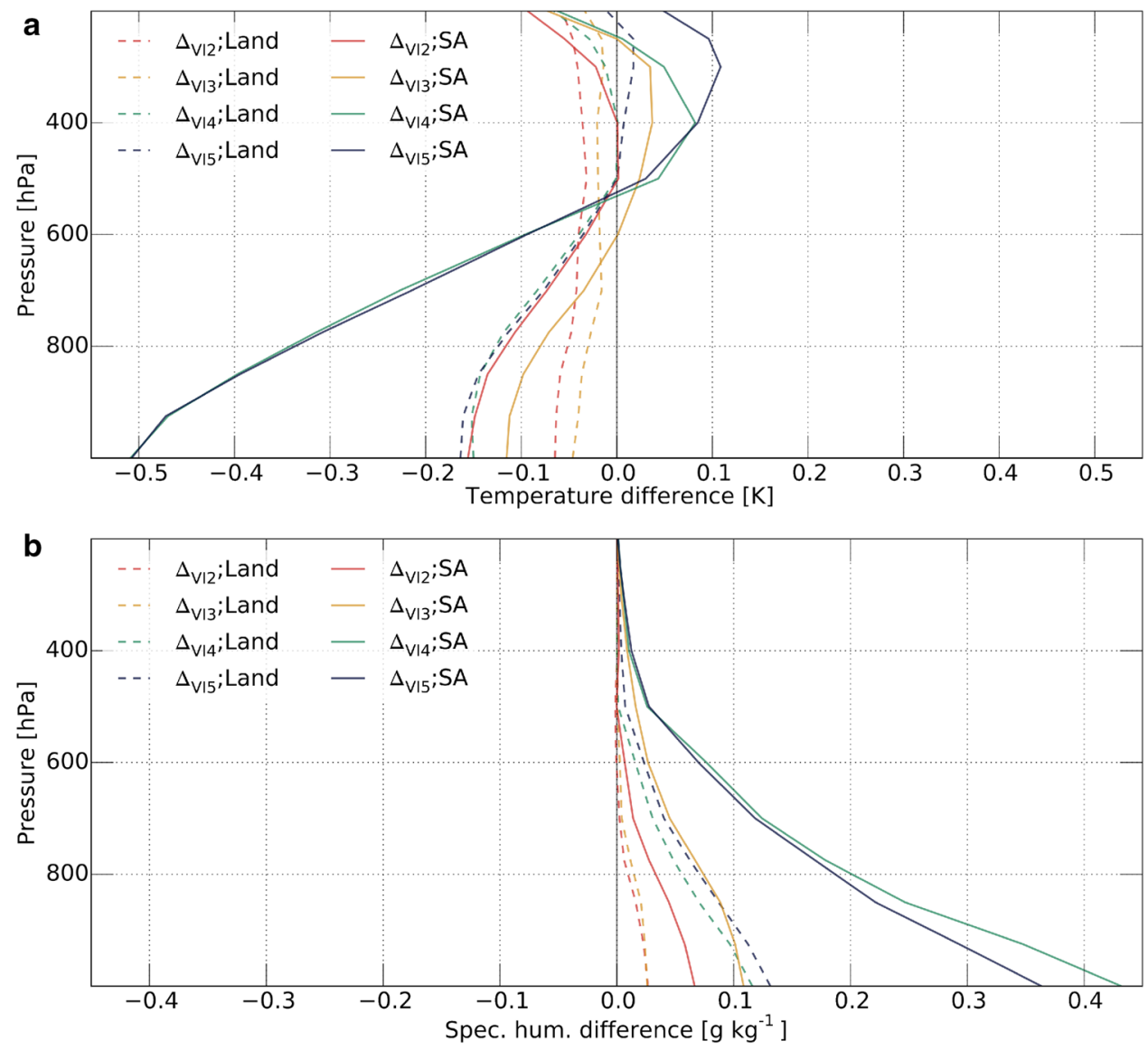
for soil moisture, is actually smaller than $\sigma_{P S V 1}$. For the entire land surface, the uncertainty with respect to the representation of irrigation characteristics is slightly larger, but with values ranging between 0.33 and $0.6, \Phi_{\mathrm{V} 1-5}$ is still substantially smaller than $\Phi_{\mathrm{PSV} 1}$, both for the entire land surface but also for the SA region.

Not only the state of the surface but also the state of the atmosphere is strongly influenced by the representation of the irrigation characteristics (Fig. 5). In the SA region, effects due to irrigation are comparable to the those in $V_{I 1}$, i.e. an increase in atmospheric water vapour, a cooling in the lower atmosphere, and a less pronounced cooling or possibly a warming higher up. However, $\Delta_{V 2}, \Delta_{V 3}, \Delta_{V 4}$ and $\Delta_{V 5}$ exhibit exceedingly different magnitudes. The largest impact on the atmospheric specific humidity can be found for $\Delta_{V 5}$, with an increase of over $0.4 \mathrm{~g} \mathrm{~kg}^{-1}$ close to the surface. This increase is not only about five times larger than for $\Delta_{V 2}$, but also more than twice as large as for $\Delta_{V 1}$. For temperatures in the lower atmosphere, the largest impact can also be seen for $\Delta_{V 5}$. Close to the surface $\Delta_{V 5}$ gives a cooling of more than $0.5 \mathrm{~K}$ which is about 4.5 times larger than for $\Delta_{V 3}$ and more than twice as large as for $\Delta_{V 1}$. Higher up in the atmosphere, $\Delta_{V 4}$ gives a warming due to irrigation of about $0.1 \mathrm{~K}$, whereas $\Delta_{V 3}$ indicates a much smaller temperature increase and for $\Delta_{V 2}$ temperatures are actually colder throughout the entire vertical column.

There are also distinct differences due to the representation of timing of irrigation, i.e. between $\Delta_{V 2}$ and $\Delta_{V 3}$. For example, for specific humidity in the SA region, $\Delta_{V 3}$ is about $50 \%$ larger than $\Delta_{V 2}$. Finally, there are also distinct differences between $\Delta_{V 4}$ and $\Delta_{V 5}$, but these are related to the seasonality of the impacts (Fig. 6). For example, when comparing differences in atmospheric winter temperature in the SA region, $\Delta_{V 4}$ close to the surface is more than twice as large as $\Delta_{V 5}$. With respect to specific humidity during autumn in the SA region, $\Delta_{V 4}$ is also about $50 \%$ larger than $\Delta_{V 5}$.

\section{Summary and conclusion}

An accurate representation of irrigation in models is key for addressing issues related to food security, fresh water resources and climate. For climate models this is especially relevant as certain temperature biases may be related to the absence of irrigation within many ESMs. For example, including irrigation into the MPI-ESM reduced the model's surface temperature bias [compared to WATCH forcing
Fig. 6 20-year seasonal mean differences between irrigation runs $V_{I 4}$ and $V_{I 5}$ and reference run $V_{R}$ a winter and summer temperature, b autumn and summer specific humidity; solid lines refer to the $\mathrm{SA}$ region $\left(40^{\circ} \mathrm{E}-130^{\circ} \mathrm{E} ; 0^{\circ} \mathrm{N}-45^{\circ} \mathrm{N}\right)$, dashed lines to the entire land surface
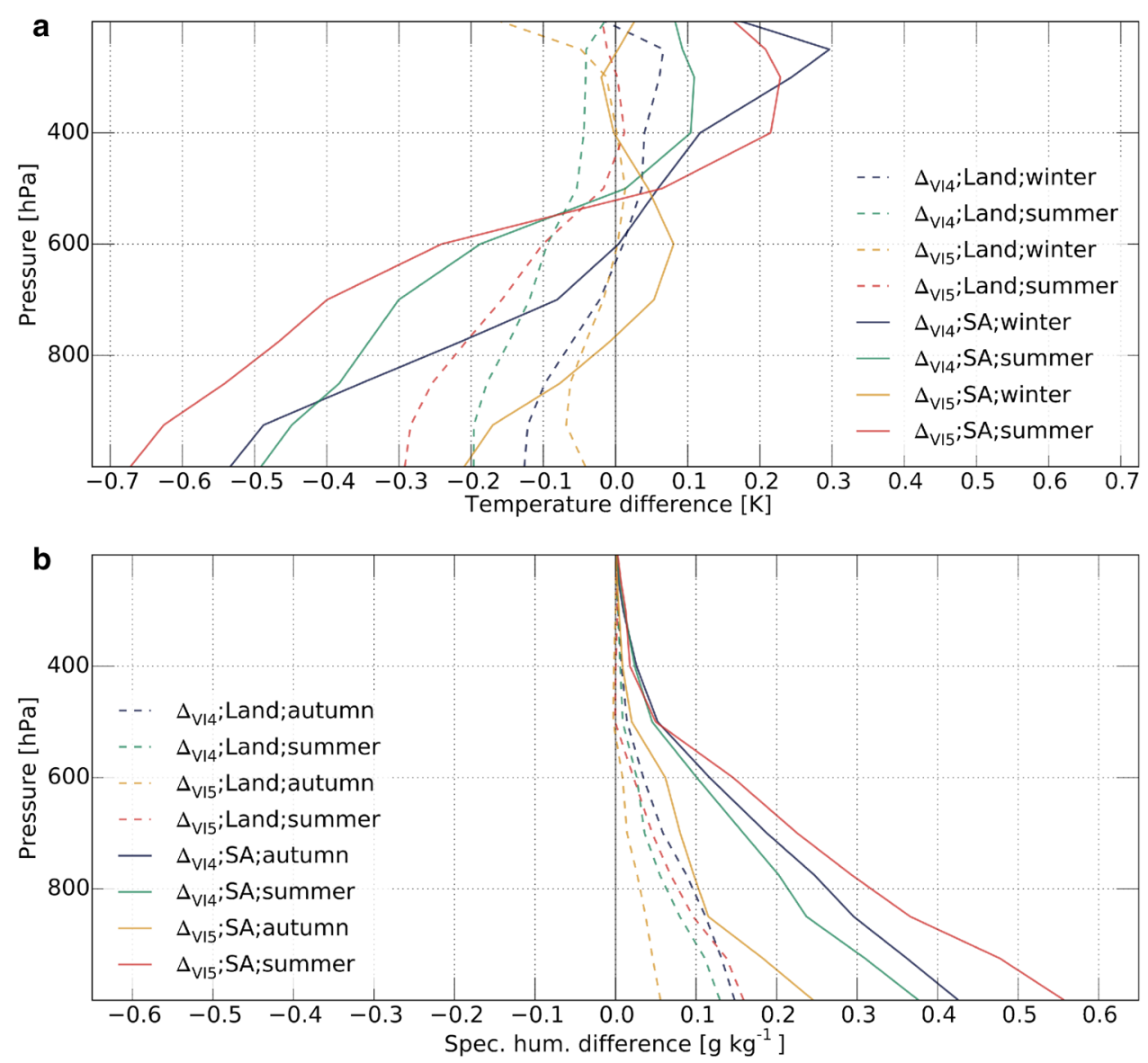
data (Weedon et al. 2011)] in the SA region by up to $0.28 \mathrm{~K}$ $(\approx 11 \%)$.

We identified two main sources of uncertainty when investigating the effects of irrigation with global climate models. One source pertains to the model's more general structure and to parametrizations that are not necessarily related to the representation of irrigation but that may severely affect the impact of irrigation on the simulated climate. The second source of uncertainty is related to the need for simplifying assumptions in an any irrigation scheme. To address these uncertainties, the land surface model JSBACH was equipped with a scheme that represents irrigation by maintaining the soil moisture in irrigated areas at a certain threshold, i.e. for most simulations the level at which potential transpiration occurs.

In order to estimate possible uncertainties with regard to the model's structure, an experiment was conducted in which for three simulations the land-surface-atmosphere coupling was varied (parameter aggregation, a simple flux aggregation and an improved flux aggregation scheme, the VERTEX scheme), while the irrigation characteristics were kept identical. A second experiment was conducted to estimate possible uncertainties related to the representation of irrigation characteristics. Here, in four simulations the irrigation effectiveness and the timing of delivery were varied. In these simulations, the coupling scheme and the actual share of the surface covered by irrigated crops, were kept the same.

With the first experiment it could be shown that the magnitude of a possible impact of irrigation on the state of the land surface depends strongly on the coupling scheme used. For example, in the simulation using the parameter aggregation scheme only abut $5.0 \%$ of the land surface in South and Southeast Asia (SA region; $40^{\circ} \mathrm{E}-130^{\circ} \mathrm{E} ; 0^{\circ} \mathrm{N}-45^{\circ} \mathrm{N}$ ) exhibit a robust impact due to irrigation whereas this area constitutes around a quarter of the land surface when using the VERTEX scheme. Also the effect on the mean state of the land surface differs substantially for the different coupling schemes. The average irrigation induced (land) surface cooling in the SA region ranges between -0.05 and $-0.28 \mathrm{~K}$ and the increase in evapotranspiration between $0.01 \mathrm{~mm} \mathrm{~d}^{-1}$ and $0.12 \mathrm{~mm} \mathrm{~d}^{-1}$. In some cases, the simulations do not only disagree with respect to the magnitude of possible impacts but also on the direction of the impact, i.e. the impact on IWV ranges between a decrease of $-0.09 \mathrm{~mm}$ and an increase of $0.38 \mathrm{~mm}$.

The second experiment shows that uncertainties related to the modelled irrigation characteristics, especially the irrigation effectiveness, are also substantial. In general the impact of irrigation on the state of the land surface is more than three times larger when assuming a low irrigation effectiveness than when a high effectiveness is assumed. For example, the simulated (land) surface cooling in the SA region ranges between -0.16 and $-0.69 \mathrm{~K}$. With respect to the atmospheric near surface temperature in the SA region, the impacts of irrigation with a low and a high effectiveness vary by roughly $0.4 \mathrm{~K}$, whereas the largest difference between any irrigation simulation and the respective reference simulation in the first experiment was below $0.25 \mathrm{~K}$. For some variables, such as the IWV, the impact is almost an order of magnitude larger, ranging between $0.09 \mathrm{~mm}$ in the high effectiveness simulations and $0.64 \mathrm{~mm}$ in the low effectiveness simulations.

On one hand, these results support studies which demonstrated that the choice of the irrigation method strongly affects the simulated climate impact (Lawston et al. 2015), highlighting the need to use more sophisticated irrigation schemes with region-, time-, technique- and crop-specific parametrisations also in global models. A key aspect is a variable irrigation target, required to make a distinction between different irrigation methods and possibly between different stages of the growing season. Here, the scheme should at least allow to distinguish permanently inundated areas, which, for simulations with respect to past and present day climate, could be achieved by prescribing the observed extent of paddy fields (see e.g. FAO 2017). Furthermore, in reality irrigation is often not limited by the water demand but rather by the water availability, which is not accounted for in most models. For simulations that deal with the present day climate impact of irrigation, a suitable strategy may be to limit simulated to observed irrigation rates (Thiery et al. 2017). However, when observations are not available, e.g. in case of future scenarios, this technique is not applicable. Here, it may be necessary to constrain withdrawals to the available ground water and water from surface water bodies such as lakes and rivers, making it necessary to couple the irrigation scheme to the land surface model's hydrology component. Finally, irrigation schemes should not merely represent the supply of water to the soil, but they should also represent the effect that constructive measures have on other aspects of the model's surface hydrology, most importantly the way that embankments are used to control the surface runoff on inundated fields.

On the other hand, the results indicate that also parts of the more general model structure and its parametrizations may not be suitable to simulate irrigation. Irrigation represents a type of heterogeneity that introduces very sharp contrasts in the surface characteristics, in that it increases the water availability only in a certain fraction of the grid box. Here, it is plausible that certain schemes, such as the parameter aggregations scheme, which are employed to deal with subgrid-scale heterogeneity and the non-linearities in the respective surface processes, fail when it comes to the strong contrasts that are given for irrigation in hot and dry environments. Furthermore, our results indicate that it may not be sufficient to simulate spatial heterogeneity at the surface, 
which is the standard in most land surface models. Due to the often large characteristic length scales of irrigated areas, spatial heterogeneity is also transferred into the atmosphere, affecting the vertical transport of humidity and energy in the planetary boundary layer. The large differences between the simulations with the simple-flux aggregation scheme and the VERTEX scheme indicate that, for the typical resolution of present-day Earth system models, a more accurate representation of irrigation's climate impact requires a scheme that resolves spatial heterogeneity also in the lowest parts of the atmosphere (Molod et al. 2003; de Vrese et al. 2016b).

Acknowledgements Open access funding provided by Max Planck Society.

Open Access This article is distributed under the terms of the Creative Commons Attribution 4.0 International License (http://creativecommons.org/licenses/by/4.0/), which permits unrestricted use, distribution, and reproduction in any medium, provided you give appropriate credit to the original author(s) and the source, provide a link to the Creative Commons license, and indicate if changes were made.

\section{Appendices}

\section{A.1 Model description}

In the parameter aggregation scheme, the state of the land surface (and the soil) as well as the surface fluxes are modelled based on effective parameters valid for an entire grid box. Here, the determination of an effective grid-box mean albedo is described in Otto et al. (2011), the aggregation of the surface roughness length of different tiles follows Mason (1988), Claussen (1991) and Claussen et al. (1994) and the aggregation of soil and hydrological parameters is done according to Kabat et al. (1997) and Lemmel and Helenius (1998). The surface fluxes linking the land surface and the atmosphere, are calculated using a bulk-exchange formulation. Here, the bulk transfer coefficients are obtained with approximate analytical expressions similar to those proposed by Louis (1979).

The second option is a simple flux aggregation scheme in which spatial subgrid-scale heterogeneity is explicitly represented by individual tiles. In this approach the state of the surface and the surface fluxes are modelled for each of the tiles separately. However, it is assumed that the vertical fluxes have blended horizontally below the lowest model level of the atmosphere which interacts only with these aggregated fluxes, i.e. spatial heterogeneity does not exist within the atmosphere.

The third possibility is a coupling via the VERTEX scheme, which also accounts for spatial heterogeneity within the lowest layers of the atmosphere and further resolves the turbulent mixing process. As in the standard version of the
MPI-ESM, the atmospheric vertical fluxes are modelled by a modified version of the turbulent kinetic energy scheme described in Brinkop and Roeckner (1995), however in the VERTEX scheme the process is resolved with respect to individual tiles. The turbulent viscosity and diffusivity are described by a function of the turbulent kinetic energy, the turbulent mixing length (Blackadar 1962) and a stability function that depends on the moist Richardson number (Mellor and Yamada 1982). In the VERTEX scheme, the fluxes within the individual tiles are not treated as independent, but are assumed to blend horizontally. Thus, the vertical flux from a given tile may influence the states of all the tiles on the level above. In the VERTEX scheme the horizontal blending of the vertical turbulent fluxes is modelled based on the concept of the blending height. To determine this height, the scheme requires the characteristic horizontal length scales of surface heterogeneity. These were derived from the Global Land Cover Map 2009 (Arino et al. 2012). In the simple flux aggregation scheme and the VERTEX scheme the tiles within a grid box interact only via the vertical turbulent fluxes. Below the surface a horizontal transport of water and heat is not modelled and the soil moisture and temperature of a given tile is independent of the other tiles.

\section{A.2 Simulated impact of irrigation on the state of the atmosphere}

In the study it was found that in the simulations using a parameter aggregation, irrigation resulted in a drier and cooler atmosphere, with the largest decrease in temperature occurring higher up in the atmosphere. This indicates that the cooling of the surface and the corresponding decrease in sensible heat flux are not exclusively responsible for the cooling of the atmosphere. The lower temperatures affect the saturation vapor pressure, causing the saturation specific humidity to be lower in the irrigation scenario, while the relative humidity close to the surface increases. This facilitates the development of low and medium cloud cover (not shown) and an increase in precipitation. Therefore, more incoming solar radiation is reflected, reducing the energy available at the surface. With less energy available, the increase in evapotranspiration in the SA region is smaller than the increase in precipitation which results in a lower specific humidity also higher up in the atmosphere. This causes a reduction of condensational heating and in cloud cover higher up in the atmosphere, lowering the amount of radiation that is being absorbed. This suggests that, especially in strongly irrigated regions, the two main mechanisms discussed in Sect. 2 are not the dominant ones in $P_{I 1}$.

Additionally, it was found that the irrigation impact on the state of the atmosphere is substantially larger when using the VERTEX scheme for coupling the land surface and the atmosphere as the scheme treats the vertical mixing process 
within the lowest layers of the atmosphere differently. When resolving the turbulent mixing process with respect to spatial subgrid-scale heterogeneity $\left(V_{I 1}\right)$, the air-properties within the individual tiles are being vertically mixed at rates that depend on vertical stability on the subgrid scale. Due to the horizontal blending of the vertical fluxes, the atmospheric column within the warmer tiles is predominantly less stable than in the colder tiles facilitating the vertical transport. A stronger vertical exchange within the relatively warmer and drier tiles means that initially more sensible heat relative to moisture is being transported upwards away from the surface, while relatively more moisture remains in the near surface layers. This results in a higher relative humidity within the lower parts of the atmosphere, more cloud cover due to convection and consequently more precipitation in $V_{I 1}$ than in $S_{I 1}$. The increase in precipitation is about a third larger for $\Delta_{V 1}$ than for $\Delta_{S 1}$. As precipitation is not resolved with respect to the tiles, it increases the plant available water also in the non-irrigated tiles of the grid box. $\Delta_{V 1}$ shows an average increase in the grid-box mean soil moisture of $0.02 \mathrm{~m}$, which is roughly twice as large as the moisture increase due to irrigation for $\Delta_{S 1}$. As this strongly affects the vegetation, the increase in the vegetated fraction, especially in the SA region, is about one third larger for $\Delta_{V 1}$ (on global average $1.0 \%$ and in the SA region $4.0 \%$ ) than for $\Delta_{S 1}$ (on global average $0.7 \%$ and in the SA region $2.6 \%$ ). Due to the increased availability of water in the non-irrigated tiles of the grid box and the increase in the vegetated fraction, there is a strong increase in the grid-box mean evapotranspiration for $\Delta_{V 1}$, which is about one third larger than the increase in evapotranspiration for $\Delta_{S 1}$. Thus, the local recycling of moisture is more pronounced when using the VERTEX coupling scheme. Additionally, there are some minor differences in wind patterns (not shown), which result in differences in the spatial distribution of precipitation. The fraction of precipitation which occurs over ocean surfaces is larger for $\Delta_{S 1}$ than for $\Delta_{V 1}$. This fraction of precipitation has no positive feedback on evapotranspiration so that the increase of atmospheric water vapour for $\Delta_{S 1}$ is substantially smaller than for $\Delta_{V 1}$.

\section{References}

Arino O, Ramos Perez JJ, Kalogirou V, Bontemps S, Defourny P, Van Bogaert E (2012) Global land cover map for 2009 (GlobCover 2009). European Space Agency (ESA) \& Université catholique de Louvain (UCL), PANGAEA. https://doi.org/10.1594/ PANGAEA.787668

Best MJ, Beljaars A, Polcher J, Viterbo P (2004) A proposed structure for coupling tiled surfaces with the planetary boundary layer. J Hydrometeorol 5(6):1271-1278
Blackadar AK (1962) The vertical distribution of wind and turbulent exchange in a neutral atmosphere. J Geophys Res 67(8):3095-3102

Boucher O, Myhre G, Myhre A (2004) Direct human influence of irrigation on atmospheric water vapour and climate. Clim Dyn 22(6-7):597-603

Bouman B, Lampayan R, Tuong T (2007) Water management in irrigated rice: coping with water scarcity. Int Rice Res Inst

Brinkop S, Roeckner E (1995) Sensitivity of a general circulation model to parameterizations of cloud-turbulence interactions in the atmospheric boundary layer. Tellus A 47(2):197-220

Brovkin V, Raddatz T, Reick CH, Claussen M, Gayler V (2009) Global biogeophysical interactions between forest and climate. Geophys Res Lett 36(L07405):1-5

Claussen M (1991) Estimation of areally-averaged surface fluxes. Bound Layer Meteorol 54(4):387-410

Claussen M, Lohmann U, Roeckner E, Schulzweida U (1994) A global dataset of land surface parameters. Tech. Rep., Max-Planck-Institute for Meteorology

Cook BI, Puma MJ, Krakauer NY (2011) Irrigation induced surface cooling in the context of modern and increased greenhouse gas forcing. Clim Dyn 37(7-8):1587-1600

Cook BI, Shukla SP, Puma MJ, Nazarenko LS (2014) Irrigation as an historical climate forcing. Clim Dyn 44(5-6):1715-1730

de Vrese P, Hagemann S (2016) Explicit representation of spatial subgrid-scale heterogeneity in an ESM. J Hydrometeorol 17(5): 13571371

de Vrese P, Hagemann S, Claussen M (2016a) Asian irrigation, African rain: remote impacts of irrigation. Geophys Res Lett 43(8):3737-3745

de Vrese P, Schulz JP, Hagemann S (2016b) On the representation of heterogeneity in land-surface-atmosphere coupling. Bound Layer Meteorol 160(1):157-183

Döll P, Siebert S (2002) Global modeling of irrigation water requirements. Water Resour Res 38(4):8-1-8-10

Douglas E, Niyogi D, Frolking S, Yeluripati J, Pielke RA, Niyogi N, Vörösmarty C, Mohanty U (2006) Changes in moisture and energy fluxes due to agricultural land use and irrigation in the indian monsoon belt. Geophys Res Lett 33(14)

Douglas E, Beltrán-Przekurat A, Niyogi D, Pielke R Sr, Vörösmarty C (2009) The impact of agricultural intensification and irrigation on land-atmosphere interactions and indian monsoon precipitationa mesoscale modeling perspective. Glob Planet Change 67(1):117-128

FAO (2017) Faostat-crops. http://www.fao.org/faostat/en/\#data/QC. Accessed 07 Oct 2017

Gates WL, Boyle JS, Covey C, Dease CG, Doutriaux CM, Drach RS, Fiorino M, Gleckler PJ, Hnilo JJ, Marlais SM, Phillips TJ, Potter GL, Santer BD, Sperber KR, Taylor KE, Williams DN (1999) An overview of the results of the atmospheric model intercomparison project (AMIP I). Bull Am Meteorol Soc 80(1):29-55

Gordon LJ, Steffen W, Jönsson BF, Folke C, Falkenmark M, Johannessen $\AA$ (2005) Human modification of global water vapor flows from the land surface. Proc Nat Acad Sci USA 102(21):7612-7617

Hagemann S, Loew A, Andersson A (2013) Combined evaluation of MPI-ESM land surface water and energy fluxes. J Adv Model Earth Syst 5(2):259-286

Hagemann S, Blome T, Saeed F, Stacke T (2014) Perspectives in modelling climate-hydrology interactions. Space sciences series of ISSI, pp 739-764

Jensen ME (2007) Beyond irrigation efficiency. Irrig Sci 25(3):233245

Kabat P, Hutjes R, Feddes R (1997) The scaling characteristics of soil parameters: from plot scale heterogeneity to subgrid parameterization. J Hydrol 190(3-4):363-396 
Krakauer NY, Puma MJ, Cook BI, Gentine P, Nazarenko L (2016) Ocean-atmosphere interactions modulate irrigations climate impacts. Earth Syst Dyn 7(4):863-876

Kueppers LM, Snyder MA, Sloan LC (2007) Irrigation cooling effect: regional climate forcing by land-use change. Geophys Res Lett 34(3)

Lawston PM, Santanello JA Jr, Zaitchik BF, Rodell M (2015) Impact of irrigation methods on land surface model spinup and initialization of WRF forecasts. J Hydrometeorol 16(3):1135-1154

Lee E, Chase TN, Rajagopalan B, Barry RG, Biggs TW, Lawrence PJ (2009) Effects of irrigation and vegetation activity on early Indian summer monsoon variability. Int J Climatol 29(4):573-581

Lemmel R, Helenius N (eds) (1998) Large-scale field experiments to improve land surface parameterisations. In: Proceedings of the second international conference on climate and water

Liu J, Yang H (2010) Spatially explicit assessment of global consumptive water uses in cropland: green and blue water. J Hydrol 384(3):187-197

Lobell D, Bala G, Bonfils C, Duffy P (2006a) Potential bias of model projected greenhouse warming in irrigated regions. Geophys Res Lett 33(13)

Lobell D, Bala G, Duffy P (2006b) Biogeophysical impacts of cropland management changes on climate. Geophys Res Lett 33(6)

Lobell D, Bala G, Mirin A, Phillips T, Maxwell R, Rotman D (2009) Regional differences in the influence of irrigation on climate. $\mathrm{J}$ Clim 22(8):2248-2255

Louis JF (1979) A parametric model of vertical eddy fluxes in the atmosphere. Bound Layer Meteorol 17(2):187-202

Mason PJ (1988) The formation of areally-averaged roughness lengths. Q J R Meteorol Soc 114(480):399-420

Mellor GL, Yamada T (1982) Development of a turbulence closure model for geophysical fluid problems. Rev Geophys 20(4):851-875

Molod A, Salmun H, Waugh DW (2003) A new look at modeling surface heterogeneity: extending its influence in the vertical. J Hydrometeorol 4(5):810-825

Niyogi D, Kishtawal C, Tripathi S, Govindaraju RS (2010) Observational evidence that agricultural intensification and land use change may be reducing the Indian summer monsoon rainfall. Water Resour Res 46(3):1-17

Otto J, Raddatz T, Claussen M (2011) Strength of forest-albedo feedback in mid-holocene climate simulations. Clim Past 7(3):1027-1039

Polcher J, McAvaney B, Viterbo P, Gaertner MA, Hahmann A, Mahfouf JF, Noilhan J, Phillips T, Pitman A, Schlosser C, Schulz JP, Timbal B, Verseghy D, Xue Y (1998) A proposal for a general interface between land surface schemes and general circulation models. Glob Planet Change 19(1-4):261-276

Puma MJ, Cook BI (2010) Effects of irrigation on global climate during the 20th century. J Geophys Res [Atmos] 115(D16)

Raddatz T, Reick C, Knorr W, Kattge J, Roeckner E, Schnur R, Schnitzler KG, Wetzel P, Jungclaus J (2007) Will the tropical land biosphere dominate the climate-carbon cycle feedback during the twenty-first century? Clim Dyn 29(6):565-574

Roeckner E, Arpe K, Bengtsson L, Christoph M, Claussen M, Dumenil L, Esch M, Giorgetta M, Schlese U, Schulzweida U (1996) The atmospheric general circulation model ECHAM4: model description and simulation of present-day climate. MPI Rep 218:1-90

Sacks WJ, Cook BI, Buenning N, Levis S, Helkowski JH (2009) Effects of global irrigation on the near-surface climate. Clim Dyn 33(2-3):159-175
Saeed F (2011) Impact of irrigation on south Asian monsoon climate. $\mathrm{PhD}$ thesis, University of Hamburg

Saeed F, Hagemann S, Jacob D (2009) Impact of irrigation on the south Asian summer monsoon. Geophys Res Lett 36(20)

Saeed F, Hagemann S, Saeed S, Jacob D (2013) Influence of midlatitude circulation on upper indus basin precipitation: the explicit role of irrigation. Clim Dyn 40(1-2):21-38

Seckler D, Amarasinghe U, Molden D, de Silva RRB (1998) World water demand and supply, 1990 to 2025: scenarios and issues, vol 19. IWMI

Seneviratne SI, Corti T, Davin EL, Hirschi M, Jaeger EB, Lehner I, Orlowsky B, Teuling AJ (2010) Investigating soil moistureclimate interactions in a changing climate: a review. Earth Sci Rev 99(3-4):125161

Shiklomanov IA (2000) Appraisal and assessment of world water resources. Water Int 25(1):11-32

Siebert S, Döll P, Hoogeveen J, Faures JM, Frenken K, Feick S (2005) Development and validation of the global map of irrigation areas. HESSD 2(4):1299-1327

Siebert S, Henrich V, Frenken K, Burke J (2013) Global map of irrigation areas version 5. Rheinische Friedrich-Wilhelms-University, Bonn, Germany/Food and Agriculture Organization of the United Nations, Rome, Italy

Stevens B, Giorgetta M, Esch M, Mauritsen T, Crueger T, Rast S, Salzmann M, Schmidt H, Bader J, Block K, Brokopf R, Fast I, Kinne S, Kornblueh L, Lohmann U, Pincus R, Reichler T, Roeckner E (2013) Atmospheric component of the MPI-M earth system model: ECHAM6. J Adv Model Earth Syst 5(2):146-172

Tatalovic M (2009) Irrigation reform needed in Asia. Nature News. http://www.nature.com/news/2009/090817/full/news.2009.826. html. Accessed 02 Nov 2017

Thiery W, Davin EL, Lawrence DM, Hirsch AL, Hauser M, Seneviratne SI (2017) Present-day irrigation mitigates heat extremes. J Geophys Res Atmos 122(3):14031422. https://doi. org/10.1002/2016jd025740

Tiwari VM, Wahr J, Swenson S (2009) Dwindling groundwater resources in northern India, from satellite gravity observations. Geophys Res Lett 36(18):1-5

Tuinenburg O, Hutjes R, Stacke T, Wiltshire A, Lucas-Picher P (2014) Effects of irrigation in india on the atmospheric water budget. J Hydrometeorol 15(3):1028-1050

Wada Y, Beek L, Bierkens MF (2012) Nonsustainable groundwater sustaining irrigation: a global assessment. Water Resour Res 48(6)

Wada Y, Wisser D, Eisner S, Flörke M, Gerten D, Haddeland I, Hanasaki N, Masaki Y, Portmann FT, Stacke T et al (2013) Multimodel projections and uncertainties of irrigation water demand under climate change. Geophys Res Lett 40(17):4626-4632

Weedon GP, Gomes S, Viterbo P, Shuttleworth WJ, Blyth E, Oesterle H, Adam JC, Bellouin N, Boucher O, Best M (2011) Creation of the watch forcing data and its use to assess global and regional reference crop evaporation over land during the twentieth century. J Hydrometeorol 12(5):823-848

Wei J, Dirmeyer PA, Wisser D, Bosilovich MG, Mocko DM (2013) Where does the irrigation water go? An estimate of the contribution of irrigation to precipitation using MERRA. J Hydrometeorol 14(1):275-289

Yoshikawa S, Cho J, Yamada H, Hanasaki N, Khajuria A, Kanae S (2013) An assessment of global net irrigation water requirements from various water supply sources to sustain irrigation: rivers and reservoirs (1960-2000 and 2050). HESSD 10(1):1251-1288 